\title{
Construction Stability Analysis of Curved Continuous Rigid Frame Bridges with High Piers
}

\author{
Guohua Song ${ }^{1}$, Minghui $\mathrm{Li}^{2}$ and Delu Che ${ }^{3}$ \\ ${ }^{1}$ School of Civil Engineering, Zhengzhou University, 450001,Zhengzhou, China \\ ${ }^{2}$ The First Construction Co., LTD of China Construction First Group, 201100, Shanghai, China \\ ${ }^{3}$ THenan Provincial Communications Planning and Design Institute Co., LTD, 450000, Zhengzhou, China
}

\begin{abstract}
Taking the curved continuous rigid frame bridges (CRFBs) with high piers as research object, the construction stability of four different styles of main piers were analyzed by finite element (FE) method in three construction stages including the segment 0 stage, largest cantilever stage, and finished bridge stage. Rules governing the stabilities of bridges with various pier styles, height, and slenderness ratio were established. At different construction stages, pier type and pier height affect structural stability differently. Wind loads have little influence on structural stability at any construction stage, and accidental events influence the stability of bridges more than normal construction loads. There is a nonlinear power relationship of fixed functional type between the stability safety factor (SSF) and slenderness ratio in all four pier styles; this power relationship can be used to predict the stability of a new pier.
\end{abstract}

\section{Introduction}

Rapid economic advancement in China has created increasing demand for new road traffic construction. In Western China or remote mountainous regions, however, bridges have to span rivers, valleys, and other complex terrain. Long-span continuous rigid-frame bridges (CRFBs) are common in these areas, containing piers that are often over one hundred meters high. Long-span CRFBs have flexural structure, low cost, good adaptability, and facilitate smooth and comfortable driving. The high piers must be sufficiently flexible to ensure safely low internal forces and to minimize unwanted mechanical influence on the superstructure due to temperature, shrinkage, concrete creep, or natural disasters such as earthquakes. The piers are typically built with small sections to accommodate their tall height, generally with a height to span ratio of less than $1 / 10$. The pier height must be even taller when a bridge crosses a mountain or deep body of water. Curved CRFBs with piers more than 50 meters high require cantilever construction technology, longer spans, and more box sections; they are also influenced by curvature, so their overall stability and local stability have considerable impact on the safety of their construction and maintenance. The overall stiffness and local stiffness of these bridges tend to be weak and must be mitigated accordingly.

Several previous researchers have studied the influence of different loads on CRFBs [1]-[4] and analyzed their structural stabilities in different construction stages [5]-[11]. Some have also discussed the mechanical principles and various methods of analyzing them [8], [12]. Others have investigated the influence of main pier design parameters on stability [3], [10], [11]. Many have conducted extensive studies on stability and continuously improved the materials and configurations of CRFBs [13]. There have been relatively few studies focused specifically on curved CRFBs [9], [10], however. C. S. Jason and his co-workers [14]-[16] have studied the stresses, behavior, and analysis method of curved steel I-girders bridges during lifting, but the construction stability of curved CRFBs is still to be investigated.

Curved CRFBs with high piers represent a combination of the advantages of curved girder bridges and CRFBs. The main span of a curved CRFB is continuous; its upper girder and lower piers are consolidated. The consolidation system allows girders and piers to bear loads simultaneously, but the type of pier substantially influences the internal forces and deformation to the bridge.

In order to investigate the construction stability of curved CRFBs, we assessed the influence of construction loads, wind loads, and other accidental loads during construction on structure stability. We used a curved CRFB in mountainous area of Western China as a practical engineering prototype, and ran the finite element (FE) program Midas/civil to build bridge models in three construction stages including the segment 0 stage, largest cantilever stage, and finished bridge stage. The construction stabilities of the models and their 
relationships with pier parameters were analyzed and several conclusions were drawn as discussed below.

\section{Stability theories}

CRFBs with high piers are a typical beam-column structure which features extrema point instability. When the structure is in an initial equilibrium state, plastic deformation occurs at high stress areas and continues to increase as the load on the structure increases. When the load reaches a certain value, the deformation rapidly spikes even as the load remains the same - at this point, the bridge is in danger of structural failure. This process can be expressed numerically as follows:

$$
\left(\left[K_{\mathrm{D}}\right]+\left[K_{\mathrm{G}}\right]\right)\{\delta\}=\{F\}
$$

where $\left[K_{\mathrm{D}}\right]$ is the element geometric stiffness matrix; $\left[K_{\mathrm{G}}\right]$ is the initial stress stiffness matrix; $\{\delta\}$ is the nodal displacement array; and $\{F\}$ is the internal force array on members.

Suppose $\{F\}$ increases $k$ times. $\left[K_{\mathrm{G}}\right]$ will also increase $k$ times, so:

$$
\left(\left[K_{\mathrm{D}}\right]+k\left[K_{\mathrm{G}}\right]\right)\{\delta\}=k\{F\}
$$

If $k$ is sufficiently large, the structure can maintain an indifferent equilibrium sate. That is, when $\{\delta\}$ develops to $\{\delta+\Delta \delta\}$, equation (2) can be rewritten as follows:

$$
\left(\left[K_{\mathrm{D}}\right]+k\left[K_{\mathrm{G}}\right]\right)\{\delta+\Delta \delta\}=k\{F\}
$$

The condition satisfying equation (2) and equation (3) simultaneously is:

$$
\left(\left[K_{\mathrm{D}}\right]+k\left[K_{\mathrm{G}}\right]\right)\{\Delta \delta\}=0
$$

Equation (4) is the characteristic equation for computing stability safety factor (SSF). If the equation has $n$ orders, $n$ eigenvalues will exist as $k_{1}, k_{2}, \ldots, k_{n}$. In a practical engineering case, only the minimum eigenvalue $k_{1}$ has practical significance, so the minimum eigenvalue $k_{1}$ is denoted as $k_{\text {cr }}$ or as stability safety factor $\kappa$, and $k_{\text {cr }}\{F\}$ is defined as the critical load.

Critical load is expressed via Euler's Formula as:

$$
F_{\text {cr }}=\pi^{2} E I /(\mu L)^{2}
$$

where $E I$ is structural stiffness; $\mu$ is a factor related to boundary conditions; and $L$ is member length.

SSF $\kappa$ is a direct assessment index reflecting structural stability. It can be expressed as the ratio of $\{F\}_{\text {cr }}$ to $\{F\}$ :

$$
\kappa=\{F\}_{\mathrm{cr}} / F
$$

where $\{F\}_{\text {cr }}$ is the total instability load array of structure; $\{F\}$ is the actual load array.

\section{Model building}

\subsection{Bridge design}

One curved CRFB model with high piers was built with spans of $61+104+61 \mathrm{~m}$, curvature radius of $348 \mathrm{~m}$, pier height of $63 \mathrm{~m}$, and central line of piers normal to the central line of the roadway. The superstructure had a cross slope of 5 percent and was $22 \mathrm{~m}$ wide. It was composed of two girders, each comprising a single-box single-room section with width of $11 \mathrm{~m}$ and varying height by quadratic parabola. The piers were $63 \mathrm{~m}$ high. Other design details were as follows.

\subsubsection{Design technical standards}

The highway classification was an expressway with four traffic lanes, design speed of $80 \mathrm{~km} / \mathrm{h}$, traffic load of Highway grade I, and designed flood frequency of grand bridge $1 / 200$.

\subsubsection{Main construction materials}

(1) Concrete: C50 was for superstructure, C40 was for piers and cross beams.

(2) Prestressed tendon: Prestressed tendons were considered only in the longitudinal direction with a nominal diameter of $15.2 \mathrm{~mm}$, comprised of a steel strand of seven wires with high strength and low relaxation. The tendons had elasticity module $E_{\mathrm{p}}=1.95 \times 10^{5} \mathrm{Mpa}$, standard strength $f_{\mathrm{pk}}=1860 \mathrm{Mpa}$, and less than $2.5 \%$ of stress relaxation rate in 1000 hours; a large tonnage grouped anchor system and vacuum mortar suction technique were used to fabricate them.

(3) Rebars: The main reinforcements were HRB400.

(4) Bearings: Seismic steel bearings were used for end bearings; WKJ-QZ4000DX for the inner side and WKJ-QZ4000SX for the outer side.

\subsubsection{Box girder size}

A continuous rigid-frame girder with varying sections was used in the superstructure. The baseboard thickness d varied uniformly from $80 \mathrm{~cm}$ at the pier-top section to 25 $\mathrm{cm}$ at the midspan section, the web thickness $t$ varied uniformly from $70 \mathrm{~cm}$ at the pier-top section to $50 \mathrm{~cm}$ at the midspan section, and the girder width $h$ varied by quadratic parabola from $6 \mathrm{~m}$ at the pier-top section to 2.3 $\mathrm{m}$ at the midspan section. The girder had a top board 11 $\mathrm{m}$ wide, a base board $6 \mathrm{~m}$ wide, and two cantilevers 2.5 $\mathrm{m}$ long. The detailed section size of the girder is shown in Figure 1.

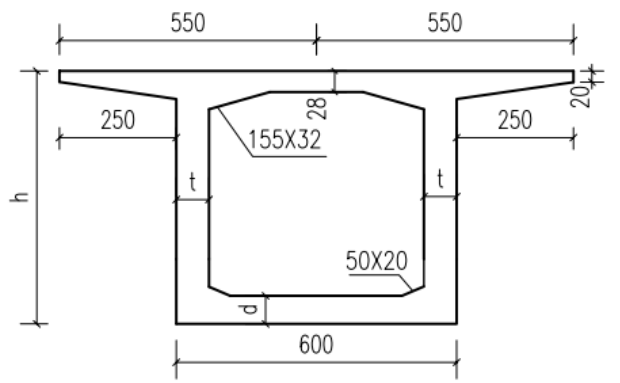

Figure 1. Cross section of box girder at pier top (unit: $\mathrm{cm}$ ).

\subsubsection{Piers}

The piers of the bridge were double-limb thin-walled piers with cross beams. Each limb had a rectangular cross 
section of $2 \times 6 \mathrm{~m}$ and the distance between two limbs was $5 \mathrm{~m}$. There was a cross beam with an interval of 21 meters between any two limbs.

\subsubsection{Construction process}

The prestressed curved CRFB was constructed in order as the pile foundation and caps, piers, and casting segment 0 . All segments but the closure segment and cast-in-site segment on the side span were cast successively via hanging basket cantilever pour symmetrically. Eleven segments were constructed on both sides simultaneously. The steel tendons were prestressed after each segment was finished. This process continued until the largest cantilever stage was completed.

\subsection{FE modeling}

We used the Midas/Civil program, which is applicable for analysis and design of bridge structures, underground structures, industrial buildings, airports, dams, harbors, and other engineered structures. We built the FE models of bridges including their superstructure, which was modeled with beam elements. The girder and piers were rigidly connected, the bottoms of piers were comprised of conventional bearings, and the supports on both ends were elastically connected according to support parameters. Analysis was conducted via the lumped mass method. The FE model of the bridge at the finished bridge stage is shown in Figure 2.

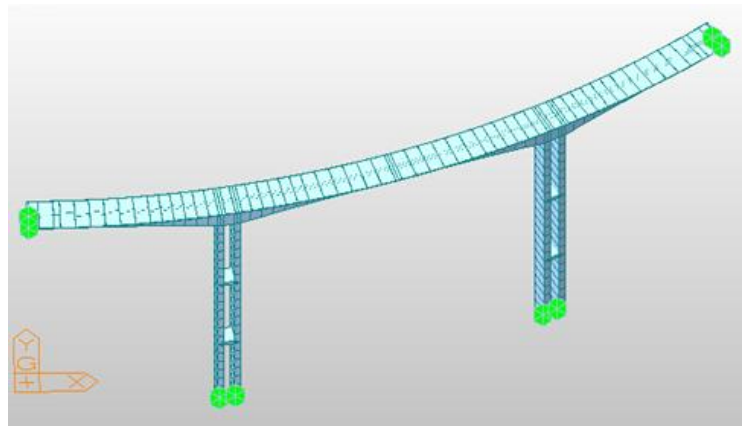

Figure 2. FE model at finished bridge stage.

\section{Stability at segment 0 stage}

\subsection{Analysis under gravity and wind loads}

The bridge becomes softer and increasingly susceptible to wind load as pier height increases. It is necessary to take wind loads into account to fully analyze structural stability in the segment 0 stage. The designed national wind pressure in the transverse direction of the pier was determined according to Wind-Resistant Design Specification for Highway Bridges (JTGT D60-01-2015) [17]. The wind loads across piers in our experiment were as follows.

Wind pressure on the piers across the bridge: $(0.68$ 1.42) $\mathrm{kN} / \mathrm{m}^{2}$, with width of piers along the bridge of $6 \mathrm{~m}$.

Wind load at pier's bottom across the bridge: 1.36 $\mathrm{kN} / \mathrm{m}$,
Wind load at pier's top across the bridge: $1.42 \mathrm{kN} / \mathrm{m}$.

According to (JTGT D60-01-2015) [17], the characteristic value of wind pressure along the bridge is 70 percent of that across the bridge; the width of piers across bridge is $2 \mathrm{~m}$, so the wind loads along the bridge are as follows.

Wind load at pier's bottom along the bridge: 2.86 $\mathrm{kN} / \mathrm{m}$,

Wind load at pier's top along the bridge: $5.96 \mathrm{kN} / \mathrm{m}$.

Diagrams of these wind loads are provided in Figure 3.

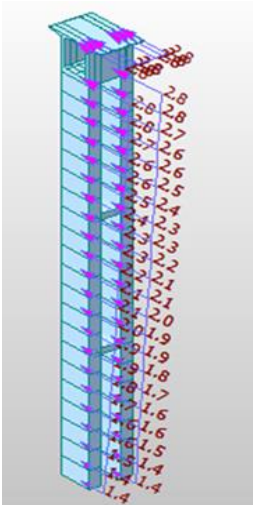

(a) Across the bridge

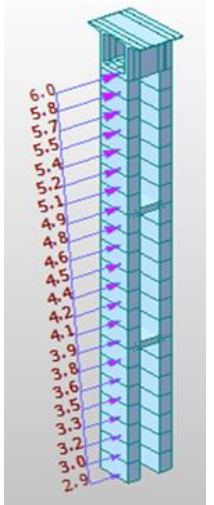

(b) Along the bridge
Figure 3. Wind load diagrams.

The load cases were classified into three types as shown in Table 1. After analysis, SSFs and first-order bucking modes were obtained as shown in Table 2 .

Table 1. Load combination at segment 0 stage.

\begin{tabular}{|c|c|}
\hline Load case No. & Load combination \\
\hline LC1-1 & (i) \\
\hline LC1-2 & (i) $+($ ii) \\
\hline LC1-3 & (i) $+($ iii) \\
\hline
\end{tabular}

Table 2. Stability at segment 0 stage under various load cases.

\begin{tabular}{|c|c|c|c|}
\hline & LC1-1 & LC1-2 & LC1-3 \\
\hline SSF & 60.27 & 60.26 & 60.26 \\
\hline $\begin{array}{c}\text { The first order of } \\
\text { buckling mode }\end{array}$ & \multicolumn{3}{|c|}{ Bucking along the bridge } \\
\hline
\end{tabular}

Table 2 shows where the overall stability of the pier is fairly uniform under wind load across the bridge or along the bridge. The first-order buckling mode of the pier extends along the bridge under all three load cases. The SSF values all well exceed 4 , indicating that the structure is reasonably stable at the segment 0 stage [18], [19].

\subsection{Influence of pier height on structural stability}

Four models of different pier types were built: A doublelimb pier with a cross beam (DLP with CB), a doublelimb pier without a cross beam (DLP without CB), a single-limb hollow pier with wall thickness of $0.5 \mathrm{~m}$ 
(SLHP with W0.5), and a single-limb hollow pier with wall thickness of $1.0 \mathrm{~m}$ (SLHP with W1.0). The cross sections of the piers are shown in Figure 4. For every type of pier, the model was built with varying height from $40 \mathrm{~m}$ to $120 \mathrm{~m}$ with an interval of $10 \mathrm{~m}$. Stability analysis was conducted under load case LC1-3 (Table 1). The SSF curves were plotted against pier height as shown in Figure 5.

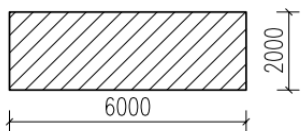

(a) One limb of

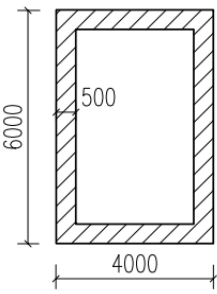

(b) SLHP with W0.5

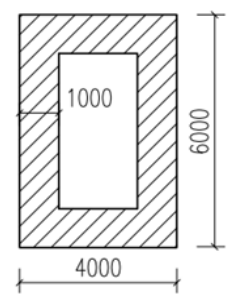

(c) SLHP
Figure 4. Cross sections of four pier types (unit: $\mathrm{mm}$ ).

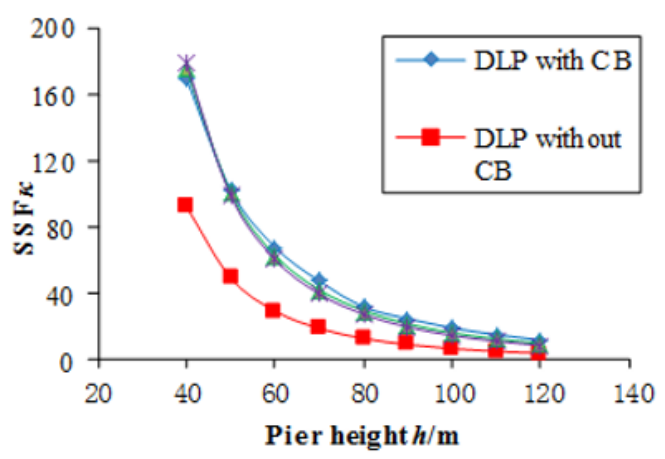

Figure 5. Curves of SSF against pier height at segment 0 stage.

\subsection{Influence of slenderness ratio on structural stability}

The SSF data $k$ were nonlinearly power-fitted and polynomial-fitted against the slenderness ratio $\lambda$ of the piers; the functions were generally fitted well [10]. For DLP with CB models, the functions could be expressed as equation (7) and equation (8) (Figure 6),

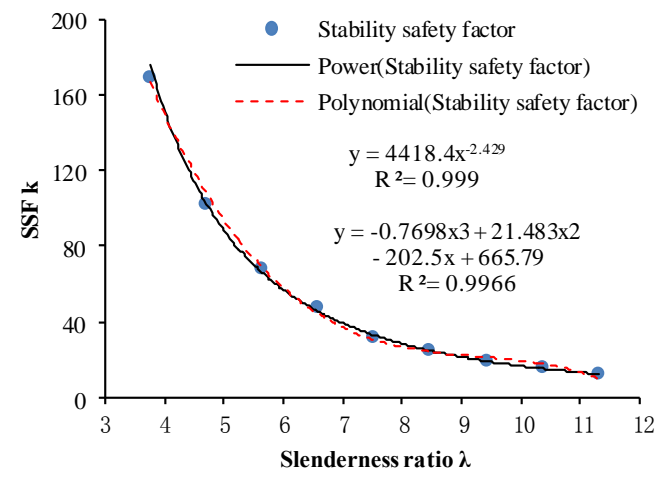

Figure 6. Different expressions of SSF vs. slenderness ratio.

$$
\begin{gathered}
k=4418.4 \lambda^{-2.429} \\
k=-0.7698 \lambda^{3}+21.483 \lambda^{2}-202.5 \lambda+665.79
\end{gathered}
$$

For a compression bar in Material Mechanics [20], the relationship between compressive stress $\sigma_{\mathrm{cr}}$ in the cross section and slenderness ratio $\lambda$ is defined as follows,

Slenderness ratio,

$$
\lambda=\mu L / i, i=(I / A)^{1 / 2}
$$

Compression stress in cross section,

$$
\sigma_{\mathrm{cr}}=\pi^{2} E / \lambda^{2}
$$

where $A, I, i$ are the area, inertia moment, and gyration radius of the compressive bar, respectively; $E, \mu$ are Poisson's ratio and the length ratio of the compressive bar, respectively.

In the design of a compressive bar, denote allowable stability stress $[\sigma]_{\text {st }}$ as the product of material strength $[\sigma]$ and SSF $\kappa$ which varies with the slenderness ratio $\lambda$ of the bar [20]. Eqaution (7) is closer to the physical interpretation of a relationship between $\kappa$ and $\lambda$ in a pier; it also fitted better per our calculations than equation (8). So we chose equation (7) as the expression of the relationship between $k$ and $\lambda$ values for all subsequent analyses.

SSF $k$ was nonlinearly fitted against slenderness ratio $\lambda$ for the four types of piers. The fitted curves are shown in Figure. 7 and are expressed in equations (11) - (14).

For DLP with CB,

$$
k=4418.4 \lambda^{-2.429}
$$

For DLP without CB

$$
k=99126 \lambda^{-2.972}
$$

For SLHP with W0.5,

$$
k=973740 \lambda^{-2.629}
$$

For SLHP with W1.0,

$$
k=2.0 \times 10^{6} \lambda^{-2.751}
$$

All the above functions of SSFs are expressed as power functions, so the following features of the power function $y=b x^{-a}$ ( $a, b$ are all positive numbers) merit further discussion here.

(1) The exponent $a$ and factor $b$ determine the curve slope. A smaller $a$ or larger $b$ (or vice versa) mean a steeper function curve (or a wider opening of the curve).

(2) The opening size of the power functional curve is determined by $a$ and $b$ together.

(3) When $a$ and $b$ are both large, the curvature of the function cannot be inferred.

Equation (12) yields the lowest value among equations (11) - (14), but the other three formulas cannot be effectively compared. The curves of $k$ versus $\lambda$ have almost the same shapes as the curves of the factor versus pier height (Figure 6), because the same set of pier data have the same height $h$.

\section{Stability at largest cantilever stage}

\subsection{Stability during construction}

We used hanging-basket cantilever construction to build the superstructure of the girder bridge. This process 
can be summarized as: constructing main pier $\rightarrow$ segment 0 of main girder $\rightarrow$ segment $1 \rightarrow$ stressing tendons of segment $1 \rightarrow$ segment $2 \rightarrow \ldots \rightarrow$ segment $11 \rightarrow$ stressingtendons of segment 11 . In short, the largest cantilever stage was the most unstable stage. All the worst load conditions had to be considered to properly assess the worst-possible construction girder $\rightarrow$ segment $1 \rightarrow$ stressing tendons of segment $1 \rightarrow$ segment 2 $\rightarrow \ldots \rightarrow$ segment $11 \rightarrow$ stressing tendons of segment 11 .

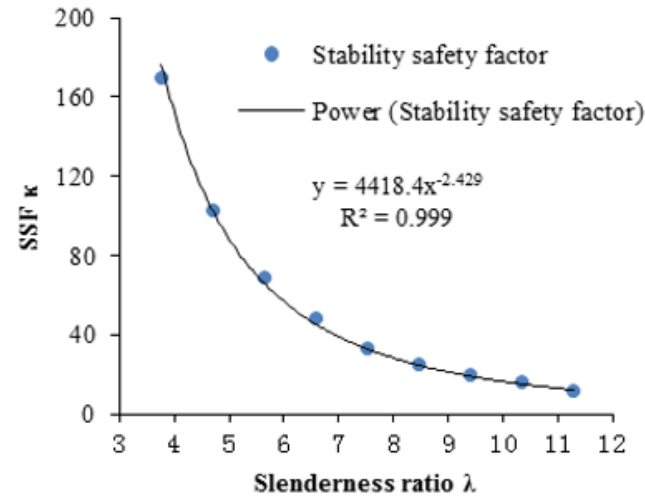

(a) DLP with CB

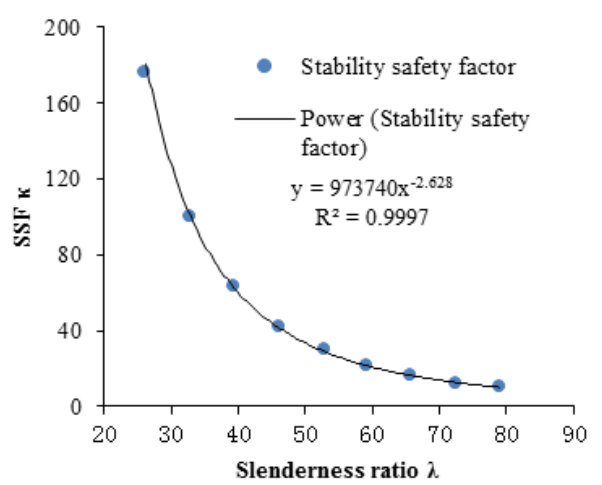

(c) SLHP with W0.5
In short, the largest cantilever stage was the most unstable stage (Figure 7). All the worst load conditions had to be scenarios in regards to structural stability. The FE model of the largest cantilever stage is shown in Figure 8. A total of 12 segments were analyzed, including pier 1 and segment 0 to segment 11 . The boundary conditions of the model were rigid solidification at the pier bottom and free at the two cantilever ends.

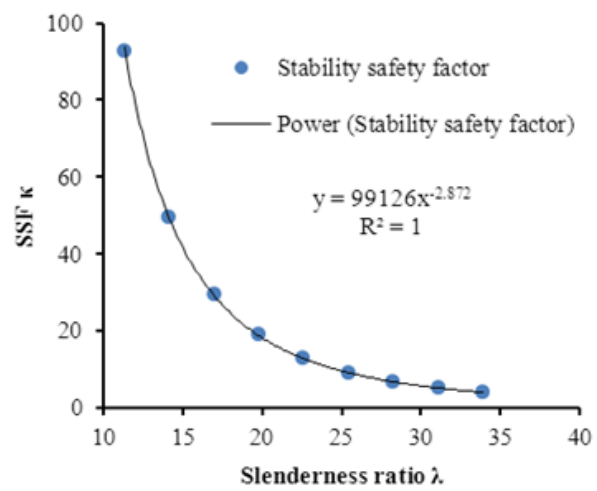

(b) DLP without CB

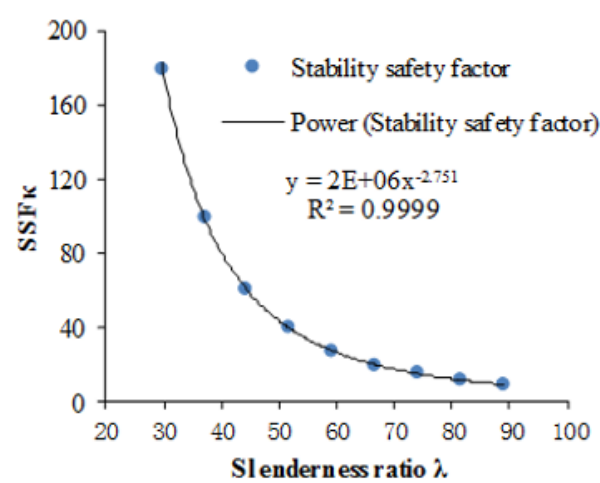

(d) SLHP with W1.0

Figure 7. Nonlinearly fitted curves of SSF against slenderness ratio at segment 0 stage.

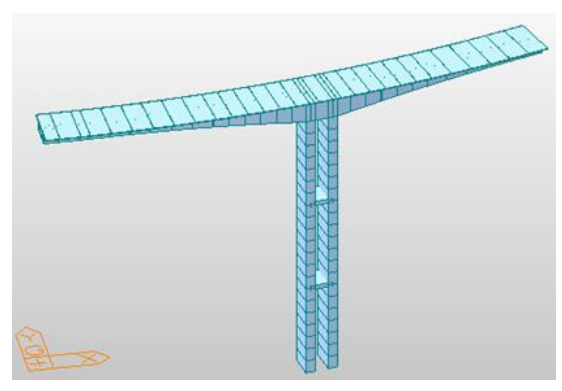

Figure 8. FE model at largest cantilever stage.

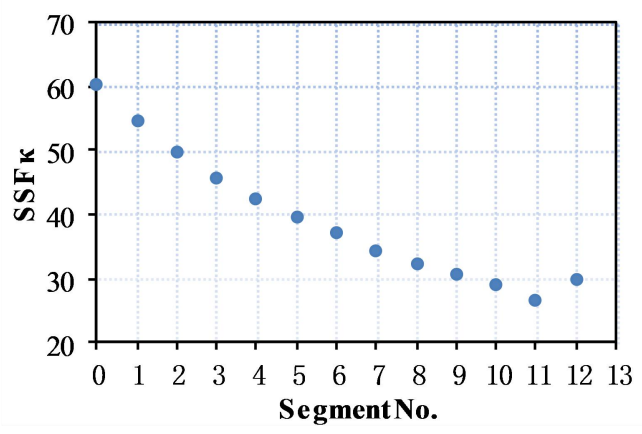

Figure 9. Stability of construction stages.

The stability throughout the construction process was analyzed from stage 0 to stage 11 , i.e., the largest cantilever stage. Models at 12 construction stages from segment 0 - 11 (where the finished bridge stage corresponds stage 12) were built and analyzed per the stability under gravity alone. The resulting SSFs are as shown in Figure 9.

As shown in Figure 9, structural stability decreases as construction progresses. It reaches a minimum at the largest cantilever stage, but is resolved at the finished bridge stage. The length and the mass of the cantilever at both sides increase along the construction process while the structure becomes softer; at finished bridge stage, however, the structure has stronger whole rigidity and stability due to the support restriction at both ends.

\subsection{Influence of construction loads on stability at largest cantilever stage}

The template is designed so that author affiliations are not repeated each time for multiple authors of the same affiliation. Please keep your affiliations as succinct as possible (for example, do not differentiate among departments of the same organization). This template was 
designed for two affiliations. Construction loads at the largest cantilever stage include: (i) Gravity; (ii) longitudinal prestressing forces; (iii) loads from construction equipment and materials placed unevenly; (iv) gravity of the hanging basket with dynamic effect (1200 kN, with dynamic coefficient of 1.2 on one side and 0.8 on the other side); (v) wind load in the lateral direction (same value as at the segment 0 stage, with wind load on the girder additionally included); (vi) wind load in the longitudinal direction (same as that of the segment 0 stage); (vii) load from a falling hanging basket (impact coefficient of 2.0); and (viii) load from unbalanced concrete pouring. When pouring the concrete of the last segment, the concrete on one cantilever had been finished while that on the other side was halffinished; the half-finished concrete was converted to node concentration forces.

The above loads were combined into comprehensive load cases as shown in Table 3 .

Table 3. Load combinations at largest cantilever stage.

\begin{tabular}{|c|c|c|}
\hline $\begin{array}{c}\text { Modeling } \\
\text { event }\end{array}$ & $\begin{array}{c}\text { Load } \\
\text { case No. }\end{array}$ & Load combination \\
\hline \multirow{5}{*}{$\begin{array}{c}\text { Casting the } \\
\text { last girder } \\
\text { segment }\end{array}$} & LC2-1 & (i) + (ii) \\
\hline & LC2-2 & (i) + (ii) + (iii) + (iv) \\
\hline & LC2-3 & (i) + (ii) + (iii) + (iv) + (viii) \\
\hline & LC2-4 & (i) + (ii) + (iii) + (iv) + (v) + (viii) \\
\hline & LC2-5 & (i) + (ii) + (iii) + (iv) + (vi) + (viii) \\
\hline \multirow{2}{*}{\begin{tabular}{|c} 
Pouring the \\
last segment \\
when \\
hanging \\
basket falls
\end{tabular}} & LC2-6 & (i) + (ii) + (iii) + (v) + (vii) + (viii) \\
\hline & LC2-7 & $\begin{array}{l}(\mathrm{i})+(\mathrm{ii})+(\mathrm{iii})+(\mathrm{vi})+(\mathrm{vii})+ \\
(\mathrm{viii})\end{array}$ \\
\hline
\end{tabular}

\subsection{Influence of pier design parameters on stability at largest cantilever stage}

The four types of pier models described in Section 3.2 were rebuilt and stability analysis was conducted under seven load cases to yield the SSFs shown in Table 4. We plotted SSF versus pier height curves under load case LC2-5 as shown in Figure 10.

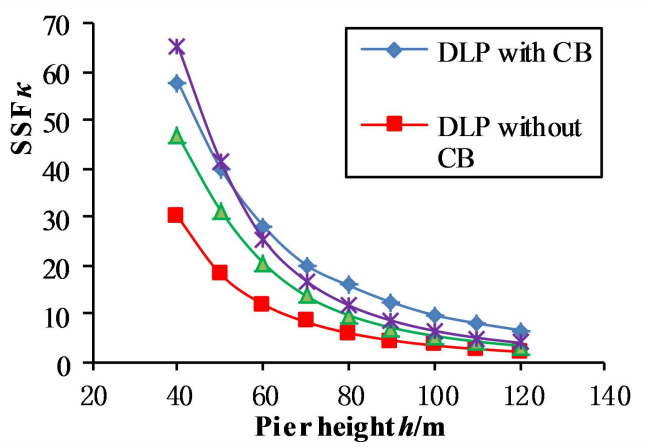

Figure 10. Curves of SSF against pier height at largest cantilever stage.

In the seven load cases shown in Table 4, the first five represent normal construction conditions; the last two represent a sudden drop of the hanging basket, i.e., accidents. The SSF is highest under dead loads such as LC2-1. Construction loads influence the structure stability under normal conditions, and SSFs become smaller under LC2-2, LC2-3, LC2-4, and LC2-5. SSFs are lowest under accident-related loads, e.g., LC2-6 and LC2-7.

Table 4. SSFs under load cases at largest cantilever stage.

\begin{tabular}{|c|c|c|}
\hline $\begin{array}{c}\text { Load case } \\
\text { No. }\end{array}$ & SSF & $\begin{array}{c}\text { The first order of } \\
\text { buckling mode }\end{array}$ \\
\hline LC2-1 & 27.57 & \multirow{1}{|}{} \\
\cline { 1 - 2 } LC2-2 & 25.79 & \\
\cline { 1 - 2 } LC2-3 & 25.38 & \multirow{2}{*}{$\begin{array}{c}\text { Pier buckling in } \\
\text { longitudinal } \\
\text { direction }\end{array}$} \\
\cline { 1 - 2 } LC2-4 & 25.36 & \multirow{2}{|}{} \\
\cline { 1 - 2 } LC2-5 & 25.38 & \\
\hline LC2-6 & 24.39 & \\
\hline LC2-7 & 24.41 & \\
\hline
\end{tabular}

Figure 10 indicates that when pier height $h<54 \mathrm{~m}$, the SSFs of SLHP with W1.0 are the highest and those of DLP with CB are second-highest. When $h>54 \mathrm{~m}$, the SSFs of DLP with CB are the highest and those of SLHP with W1.0 are second-highest. The SSFs of SLHP with W0.5 consistently fall into third place and SSFs of DLP without $\mathrm{CB}$ are always the lowest.

At the largest cantilever stage, the relationships between SSFs and pier type and height differ markedly from those at the segment 0 stage. The SSFs of two single-limb piers are close to each other. Using the same method as that described in Section 4.3, we nonlinearly fitted the relationship of SSFs and slenderness ratio using the functions defined in formulas (15) - (18).

For DLP with CB,

$$
k=845.13 \lambda^{-1.981}
$$

For DLP without CB

$$
k=9467.3 \lambda^{-2.361}
$$

For SLHP with W0.5,

$$
k=142292 \lambda^{-2.422}
$$

For SLHP with W1.0,

$$
k=376343 \lambda^{-2.542}
$$

The values of $\kappa$ cannot be ranked effectively when the independent variable $\lambda$ is constant, because they have the same characteristics as the power function $y=b x^{-a}$ when $a$ and $b$ increase or decrease simultaneously.

\section{Stability at finished bridge stage}

\subsection{Stability analysis under gravity and wind loads}

For stability analysis at the finished stage, the loads included: (i) Gravity; (ii) longitudinal prestressing forces; 
(iii) secondary dead loads; (iv) wind loads in the lateral direction; and (v) wind loads in the longitudinal direction. The load cases were split into three categories as shown in Table 5.

Table 5. Load combination at finished bridge stage.

\begin{tabular}{|c|l|}
\hline Load case No. & Load combination \\
\hline LC3-1 & (i) + (ii) + (iii) \\
\hline LC3-2 & (i) $+($ ii $)+($ iii $)+($ iv $)$ \\
\hline LC3-3 & (i) $+($ ii $)+($ iii $)+(v)$ \\
\hline
\end{tabular}

We obtained the SSFs and first-order bucking modes shown in Table 6.

Table 6. Stability at finished bridge stage under various load cases.

\begin{tabular}{|c|c|c|c|}
\hline & LC3-1 & LC3-2 & LC3-3 \\
\hline SSF & 29.424 & 29.418 & 29.413 \\
\hline $\begin{array}{c}\text { The first order } \\
\text { of } \\
\text { buckling mode }\end{array}$ & \multicolumn{3}{|c|}{ Bucking along the bridge } \\
\hline
\end{tabular}

The overall stability of the bridge is relatively stable under wind load in the lateral or longitudinal direction. The first-order buckling mode of the bridge occurs in the longitudinal direction under all three load cases.

\subsection{Influence of pier height on structural stability at finished bridge stage}

Four pier types of models were again built as described in Section 4.2. Stability analysis was conducted under load case LC3-2 to plot the SSF curves against pier height as shown in Figure 11.

Figure 11 shows that pier height has varying influence on the stability of the structure. At the finished bridge stage, two types of bridges with single-limb piers have closer stability than in the other stages we assessed. The stability of the DLP with CB bridge is greater than the other three types.

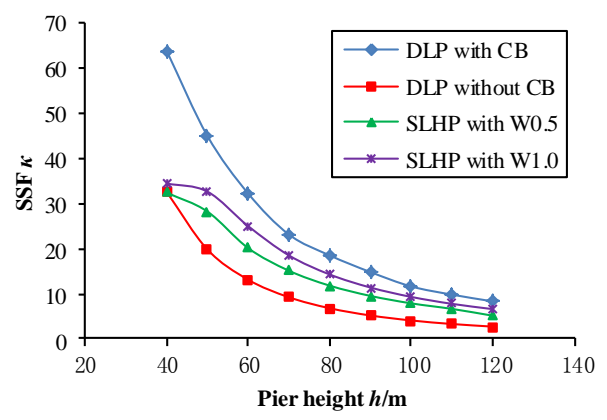

Figure 11. Curves of SSF against pier height at finished bridge stage.

We again nonlinearly fitted the SSFs and slenderness ratios using the same method as described in Section 4.3 as power functions. The functions were obtained as follows.

For DLP with CB,

$$
k=818.9 \lambda^{-1.888}
$$

For DLP without CB,

$$
k=8151.8 \lambda^{-2.275}
$$

For SLHP with W0.5,

$$
k=21378 \lambda^{-1.895}
$$

For SLHP with W1.0,

$$
k=22962 \lambda^{-1.865}
$$

The values of $k$ cannot be determined using the above formulas when the independent variable $\lambda$ is constant, because they have the same characteristics as the power function $y=b x^{-a}$ when $a$ and $b$ increase or decrease simultaneously.

\section{Conclusions}

In this study, a curved CRFB in a mountainous area of Western China was used as a practical engineering prototype to build bridge models at three different construction stages in FE software. The construction stabilities of the models and their relationships with bridge parameters were analyzed. Our conclusions can be summarized as follows.

(1) At different construction stages, pier type and pier height influence structural stability differently. The DLP with CB type has stronger stability, two types of single-limb piers have generally closer stability, and the DLP without CB type has the lowest stability. The DLP without $\mathrm{CB}$ type is not recommended for practical bridge engineering.

(2) Wind loads have relatively little influence on structural stability at any construction stage or the finished bridge stage. Accident events, such sudden drop of the hanging basket, do markedly influence the stability of the bridge more than normal construction loads.

(3) A nonlinear power functional relationship exists between SSFs and slenderness ratios for the four types of piers we assessed. This power functional relationship can be used to predict the stability of a new pier.

\section{Acknowledgment}

This work was supported by the National Natural Science Foundation of China (U1304515). The authors would also like to thank the anonymous reviewers for their valuable comments and suggestions.

\section{References}

1. J. Li, C. Bai, B. Yu, "Dynamic test and analysis of Ttype rigid bridge damage due to excess vibration," 
Journal of Highway and Transportation Research and Development, 5(2), 94-98, (2011)

2. Z. Zong , Z. Xia , H. Liu , Y. Li , X. Huang, "Collapse failure of prestressed concrete continuous rigid-frame bridge under strong earthquake excitation: testing and simulation," Journal of Bridge Engineering, ASCE, 21(9) 04016047 (15 pages), (2016) https://doi.org/ 10.1061/(ASCE)BE.19435592.0000912.

3. B. Yao, J. Dong, Z. Qi, "Natural vibration properties analysis of continuous rigid frame bridge varying with consolidation damage at pier top," In: 10th Asia Pacific Transportation Development Conference, (2014). Beijing, China. May 25-27.

4. Z. Pan, C. Fu, Y. Jiang, "Uncertainty analysis of creep and shrinkage effects in long-span continuous rigid frame of Sutong bridge," Journal of Bridge Engineering, ASCE, 16(2), 248-258, (2011) https://doi.org/10.1061/(ASCE)BE.19435592.0000147

5. J. S. Hastings, Q. H. Zhao, E. G. Burdette, "Steel girder stability during bridge erection: AASHTO LRFD check on L/b ratios," Journal of Bridge Engineering, ASCE, 15(6), 759-762, (2010) https://doi.org/10.1061/(ASCE)BE.19435592.0000102

6. Z. S. Harper, S. T. Edwards, G. R.Consolazio, K. R. Gurley, "Drag coefficients for construction-stage stability analysis of bridge girders under wind loading," Journal of Bridge Engineering, ASCE, 22(1) , 04016110: (14 Pages), (2017) https://doi.org/10.1061/(ASCE)BE.19435592.0000988

7. Q. Zhao, B. Yu, E. G. Burdette, J. S. Hastings, "Monitoring steel girder stability for safer bridge erection," Journal of Performance of Constructed Facilities, ASCE, 23(6), 391-398, (2009) https://doi.org/10.1061/(ASCE)CF.19435509.0000048

8. K.Y. Li, Z. Q. Chen, Y. Han, "Quick arithmetic of analysis of stability of double-leg thin-wall high piers during construction," Journal of the China Railway Society, 26(5), 86-90, (2004) (in Chinese with English abstract)

9. H. J. Wu, Y. Q. Kang, L. Zhang, "Analysis of sensitive factors of long-span continuous rigid frame bridge's stability with thin-wall piers in the construction stage," Advanced Materials Research, 255-260(2), 921-925, (2011)

10. J. L. Wang, S. H. He, "Nonlinear analysis of longspan curve rigid bridge with high piers during cantilever construction," Journal of Highway and Transportation Research and Development, 22(10), 64-67, (2005) (in Chinese with English abstract)

11. J. L. Wang, S. H. He, "Nonlinear stability of longspan curve rigid bridge with high piers in whole process," Journal of Chang'an University (Natural Science Edition) , 28(3), 49-52, (2008) (in Chinese with English abstract)

12. J. Zhang, Y. Tian, C. Q. Yang, B. T. Wu, Z. S. Wu, G. Wu, X. Zhang, L. M. Zhou, "Vibration and deformation monitoring of a long-span rigid-frame bridge with distributed long-gauge sensors," Journal of Aerospace Engineering, ASCE, 30(2), B4016014 (9 pages), (2017) https://doi.org/10.1061/(ASCE)AS.19435525.0000678

13. Z. P. Bazant, L. Cedolin, Stability of Structures: Elastic, Inelastic, Fracture and Damage Theories, World Scientific Publishing Co. Pte. Ltd., Singapore, (2010)

14. C. S. Jason, A. H. Todd, B. W. Eric, H. F. Karl, D. E. Michael, C. S. Andrew, F. F. Jamie, J. P. Brian, "Behavior of horizontally curved I-girders during lifting," Journal of Structural Engineering, ASCE, 139(4), 481-490, https://doi.org/10.1061/(ASCE)ST.1943541X.0000674

15. C. S. Jason, A. H. Todd, B. W. Eric, H. F. Karl, D. E. Michael, C. S. Andrew, F. F. Jamie, "Comparisons of the computed and measured behavior of curved steel I-girders during lifting," Journal of Structural Engineering, ASCE, 138(1) 1-10, (2012). https://doi.org/10.1061/(ASCE)ST.1943541X.0000417

16. D. F. Jeremiah, C. S. Jason, A. H. Todd, S. Andrew, F. Jamie, D. E. Michael, B. W. Eric, H. F. Karl, "Instrumentation of a horizontally curved steel Igirder bridge during construction," Journal of Structural Engineering, ASCE, 141(1), D4014006 (9 pages), https://doi.org/10.1061/(ASCE)ST.1943541X.0001110

17. Ministry of Transport of the People's Republic of China, Wind-Resistant Design Specification for Highway Bridges (JTGT D60-01-2015), China Communications Press, Beijing, China, (2015). (in Chinese)

18. J. Liu, Y. J. Liu, B. C. Yang, “A discussion on linear elastic stability safety coefficient of bridge structure," Journal of Guangxi University (Natural Science Edition), 34(6), 719-724, (2009) (in Chinese with English abstract)

19. X. L. Tong, Z. Fang, "Study on SSF of bridge structure based upon reliability index," Journal of the China Railway Society, 36(10), 102-108, (2014) (in Chinese with English abstract)

20. X. F. Sun, X. S. Fang, L. T. Guan, Mechanics of Materials, High Education Press, Beijing, China, (2008). (in Chinese) 